\title{
CARTOGRAPHICAL METHOD IN DIGITAL MODELLING OF HYDROGRAPHICAL CHARACTERISTICS IN THE EXAMPLE OF THE UPPER ZETABASIN
}

DOI: http://dx.doi.org/10.18509/GBP.2015.04

UDC: 528.94.02:556]:004.946(497.16)

\author{
Docent Dr. Goran Barovic ${ }^{1}$ \\ DuskoVujacic, $\mathrm{MSc}^{2}$ \\ ${ }^{1}$ Faculty of Philosophy, Nikšić, University of Montenegro, Montenegro \\ ${ }^{2}$ Office for Hydrometeorology and Seismology, Podgorica, Montenegro
}

\begin{abstract}
There have been two major milestones in cartography: first was the invention of printing machines which brought to an end the need for manual work on mapmaking, and second was the invention of modern computers that opened up developments yet undreamed of. With the computerisation of cartography, there was a steep increase in the development and progressof cartography. This led to the establishment of a new sub-discipline in cartography: digital cartography. Previously used techniques in mapmaking required: a time-consuming processof workmanship, a large number of highly specialised experts, and large and expensive equipment. The science of cartography defined procedures that have to be followed in order to transition from an idea to a map. Those procedures include various methods and means of presentation that we can use, together or alone, to reproduce a geographical space or one of its segments. A special place in the mapmaking process is reserved for the cartographical method, which defines three scientific categories that can be identified as the spatial, temporal and essential definition of the problem in question. Through these three segments, we can scientifically analyse and come to conclusions aboutthe problem being investigated and mapped.The presentation of cartographical papers through digital cartography hasgained a new dimension. Besides presenting the basic cartographical properties, by using digital modelling, we can produce 2D and 3D models. By using various display options, one can make many different models and have the possibility to analyse thecause-and-effect relationships available on a given model. The River Zeta is a watercourse in the Adriatic basin and it features many hydrological phenomena. It is the largest subterranean river in Montenegro, and in the wider area of its basin there are many karst phenomena. Some of those are the GornjePoljeWhirlpool, one of the largest estavelles in the Dinarides and Vido'sStream, an intermittent spring, also a very rare phenomenon in karst geology. The Upper Zeta basin is also known to have been modified by construction of a hydrological system in the second half of the last century, for the needs of PerucicaHydroelectric Power Plant. What makes this hydrological system so special is its location in a karst field, which is a rarity considering our knowledge of water redistribution through karst.
\end{abstract}

Keywords: cartography, digitisation, modelling, hydrological system, karst field 


\section{INTRODUCTION}

Representation of the space in which humans have lived has a very long tradition. It is well known that humans first used their fingers, charcoal orsharp stones to write in ash, sand or on the walls of caves.From there we move to treating the hides of animals, and then various types of paper. Drawing maps by hand was for a long time the only method of cartography. It was a long, difficult and expensive way of working, requiring skilful draughtsmen and much time. Gutenberg's press was a turning point in printing which also had an effect on publishing maps. Machine printing drastically reduced the time needed to publish a map, lowered its cost and increased the quality of the printed features. Printing techniques were intensively improved and made significant progress until the second half of the twentieth century, when a new era dawned for many areas of study, not least in cartographical techniques. This turning point was the development of informatics and the advantages which it enabled at all levels of cartographical study and cartographical technique. Research using computers, plotting maps using numerous software packages and printing on various types of printers has brought cartographical expression to its height. This has enabled wide application of cartographical knowledge in many fields of study, most of all in those that deal with spatial relations.

\section{CARTOGRAPHICAL METHOD}

The map is most connected with geography, and some call it "the second language of geography", but cartographical representation is used and has its application in almost all areas of science where plotting of the spatial arrangementof the elements being researched is needed.[6] Every scientific approach, including the mapping of a space, is conducted in two phases: researching the task and collating the results. The conducting of these activities is a methodological approach which leads to a realisation, the result of which is a map. When talking about cartography, the aforementioned can be transferred to the process of plotting the map and the process of using the map. A geographical map is much more than an ordinary drawing of the territory that is being researched. If the spatial relations on the map are precisely represented, it becomes a shape for studying, recording, calculating, predicting and concluding about the relationships which are joined by causeandeffect and are presented as such to the researcher. Over the years of its development, cartography as a science has developed its own special method of research and collating results which we call the cartographical method. "The cartographical method in the process of general knowledge nominatively enables the solution of the following gnoseological categories: 1. Spatial definition of the material subjects and phenomena; 2. Temporal correlation of real-world processes and phenomena and their evolutivity; 3. Essential definition of the subjects, phenomena and relationships in the real world." The first segment, spatial definition, can be considered from two aspects: spatial localisation and mutual localisation of the elements shown on the map. Spatial localisation consists in the positioning of the shown features and buildings relative to the spatial system used. This is usually an accepted coordinate system which is represented by a cartographical network. Mutual localisation is also a vital element in this segment because it allows us to define through further analysis of the map their relationships to each other. The second segment which the cartographical method enables for us is temporal correlation, which can also be considered from two aspects: precise definition of the time of representation of the features; and the choice of the time period for the mapped space. The state of the features and building at a given time are determined by 
precise definition of the temporal arrangement for the mapped space. Choosing a longer time period offers us the chance of showing possible changes which have come about in the mapped space. Finally, the third segment, the essential definition of the subject, the resolution of which is enabled for us by the cartographical method is conducted through the possibility of allocating the qualitative and quantitative characteristics of the mapped features. [6]

\section{MODELLING IN CARTOGRAPHY}

We can consider modelling anessential part of the process which should be applied in a large number of research approaches. A model is made in order to replace the subject of the research and to enable experiments to be conducted upon it, which will aid us in studying the space being considered. It is desirable to construct many models in order to look at the subject of the research from various aspects, whereby a more realistic picture of it will be gained and more reliable indicators obtained. There are several universal principles of modelling that are also valid for modelling in cartography: " 1 . The principle of the universality of the subject of modelling (every subject of the research can be modelled); 2 . The principle of model diversity (every subject or system can be modelled in different ways); and3. The principles of prototypicality and exemplarity." [7] The process of modelling in cartography is conducted according to universal approaches. The first part of modelling still consists in laying the theoretical foundations of the model, in which it is necessary to define all the important elements of the future model with the precisely defined characteristics of all the factors that we wish to represent. The second part of the modelling process consists in forming a practical model or realisation of the theoretically based tasks. Connecting informatics with cartography has led to digitisation as one of the work processes in it, as well as to a special area of cartography - digital cartography. Digital cartography has become a branch of cartography involving the use of computers to produce maps.[4] This period of development for cartography is marked by the tendency to speed up the whole process of putting together and printing maps, because it is that part that has been the longest phase in mapmaking. It was quickly noticed that the whole process cannot be automated as was thought at the start, whereupon it changed to "computer-aided processes in mapmaking".[1] The term digital cartography became the umbrella term for cartographical representations made on appropriate hardware and with the help of various software packages. Modelling through cartographical representation nowadays is one of the basic approaches that should be taken so that in planning a large number of human activities, their potential good and bad sides can be considered. There are many cartographical models that can be used and they depend on, among other things, the type of space being researched, the needs of the one commissioning the study and the quantity of information that we have available. The model may be represented in the form of: a map, a model in thematic cartography, atlases, 3D and 4D models, and a virtual reality model.[5] Connecting cartography with informatics, as was already mentioned in the introduction, is another important moment in the development of cartography as a science. However, this new method of work in cartography has its advantages and also disadvantages. There are of course many more positive effects: significant speeding up, a lower purchase cost, the ability toeasily update, add to, or correct any errors, an improvement in working conditions, the transfer of features from one projection to another, an increased number of thematic maps that can be produced in digital form, the quality of map production, increased reviewability, the 
possibility of easy searching and zooming, connection with multimedia content and widespread use. Besides the stated positive effects, we should also mention the negative ones: a possible lack of computer access, the cartographer must know how to use many software packages, the opportunity giventoeverycomputer user interested to be involved in mapmaking which can have negative effects, the screen resolution, etc. From the aforementioned it follows that there are significantly more positive effects than negative ones. The process of modelling is carried out through several phases. The first is to define the task, in which the problem that needs to be got round during this methodological approach must be clearly stated. By studying the task, it is necessary to determine which model will best solve the problem. In choosing the model, one should take care that it has as high a degree of similarity as possible with the original so that the next phase, studying the model, may provide as much data as possible, which we can use for analysing it. If possible, in installing the model it is desirable to make many different versions which will show through further analysis which of them offers the best solution to the task that has been set. Every version (the more, the better) represents a particular experiment whereby the good and bad sides should be defined, and can alert the researcher to the advantages and disadvantages of that model, affording the possibility of choosing the solution which is best.

\section{THE RIVER ZETA}

The River Zeta is the right-hand tributary of the River Morača, the largest watercourse in the Adriatic basin. The surface area of the basin region of the River Zeta is $1,216 \mathrm{~km}^{2}$ or $18.35 \%$ of the entire Adriatic basin in Montenegro. This basin region is divided into the Upper and Lower Zeta. In the Upper Zeta region, in which the most significant part extends through Nikšić Field, the last 50 years have seen a great transformation in the hydrological conditions, which is the reason this has been selected as the example in this paper. These changes came about because of the construction of artificial lakes and the channelling of part of the river's flow, all for the purpose of providing sufficient quantities of water for the needs of the Upper ZetaHydrological System. The region of NikšićField (Nikšićkopolje) is also known for its series of hydrological features which have brought this part of the Zeta's course into literature as one of the most characteristic examples of its type in the world.

The entire length of the course of the Zeta, from its source inNikšić Field, to the confluence with the Morača, extends over $72.52 \mathrm{~km}$, of which roughly $12 \mathrm{~km}$ traversesNikšić Field. The area around the source consists of six watercourses with different hydrological characteristics and lengths varying from the smallest - Boljašnica, $1.25 \mathrm{~km}$ long, to the longest - Surdup, $17.47 \mathrm{~km}$ long. In the zone of Nikšić Field, the river is fed on the left-hand side by four tributaries with large variations in all their characteristics, just as in the area around the source. The smallest is Studenac Springs (Studenačkavrela), with a length of $1.9 \mathrm{~km}$, and the longest is the River Gračanica with a length of $27.37 \mathrm{~km}$. The quantities of water that flow through these watercourses into the Zeta also varyin proportion to their lengths. In Nikšić Field, the River Zeta is fed on the right-hand side by just one tributary, the River Moštanica. The Moštanica is a watercourse originating in the zone of what was once KrupacField in the western zone of Nikšić Field, with a length of about $11 \mathrm{~km}$. [2] The basin region of the River Zeta which is located in the zone of Nikšić Field is known for its large number of hydrological phenomena. In the zone of GornjePolje (Upper Field) is an estavelle, GornjePolje Whirlpool, a hydrological 
feature which, depending on the inflow, functions sometimes as a sinkhole and sometimes as a spring, and is one of the largest of its type in the Dinarides. In the immediate vicinity of GornjePolje Whirlpool is located Vido's Brook, an intermittent karst spring (a hydrographical feature which, depending on the inflow, at the surface discharges water intermittently) and also a very rare type of hydrographical spring.

Nikšić Field is the largest karst field in Montenegro. It covers an area of roughly $66 \mathrm{~km}^{2}$ while its elevation above sea level ranges between $600 \mathrm{~m}$ and $660 \mathrm{~m}$. In the course of research undertaken so far a large number of different hydrographical features have been identified. Nikšić Field is also known for the fact that in the second half of the last century a hydrological system was constructed in it for the needs of the PerućicaHydroelectric Plant. A unique feature of this system is that it was constructed in a karst field, which is rare, given how water is known to flow in karst. [3]

\section{THE SITUATION BEFORE CHANGES IN THE HYDROGRAPHICAL CONDITIONS}

Several separate units can be clearly distinguished in Nikšić Field - the fields: GornjePolje (Upper Field), Krupac Field, Slano Field and the central part of the field. GornjePolje covers the northern part of Nikšić Field. In its higher regions the River Zeta, the largest watercourse in Nikšić Field, forms from many smaller streams. A characteristic of this part is that on its northern slopes a large number of sources have been identified, which feed into the Zeta's tributaries. Part of the spring in Vidrovan has been capped and is used for Nikšić's water supply. Krupac Field is separated from GornjePolje by Mt. Uzdomir, from the central part of the field by the Studenac Hills (Studenačkeglavice), and from Slano Field by the RidjaniFissures (Ridjanskerupe). This field is a natural depression which was often flooded by the numerous springs on its northern edge, even before the construction of the dam, while the excess water is lost through the many sinkholes in the south-western part of the field and its only outflow, the River Moštanica. Slano Field is located in the western part of Nikšić Field. It is bounded by the RidjaniFissures to the north, Kuside to the west and the northern slopes of Mt. Budoš to the south. As with Krupac Field, it is a natural depression with several indentations which from time to time used to form pools. The central part of the field, as the title itself underlines, is located in the middle and practically connects the rest of the peripheral units. GornjePolje is in the north, Krupac Field in the north-west and Slano Field in the west, as seen in figures 1 and 2.

Detailed hydrological research of Nikšić Field was carried out at the beginning of the second half of last century when preparations began for construction of the Upper Zeta Hydrological System. The very fact that in the flat part of the field and in its vicinity over 330 springs, 880 sinkholes, around 30 estavelles, one intermittent karst spring and a large number of underground hydrological connections tell their own story about the confirmed very complex conditions. 


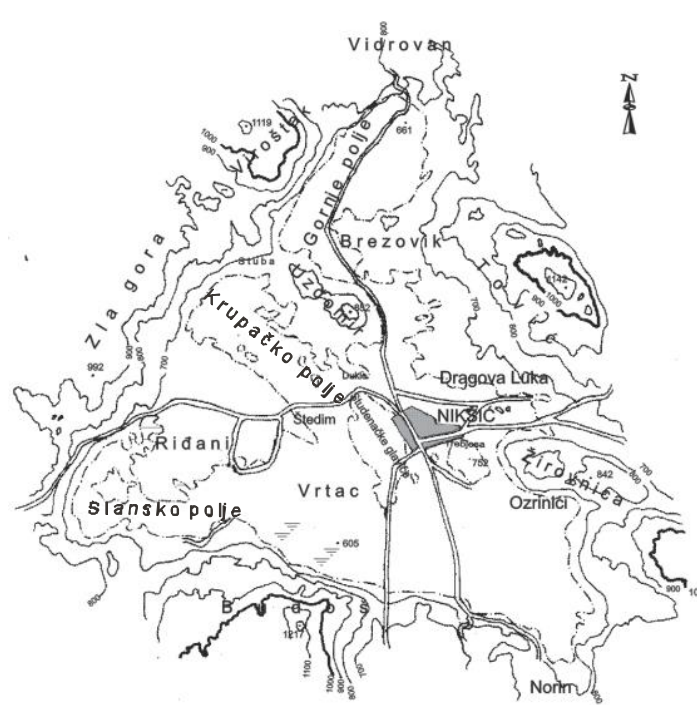

Figure 1: Overview map- model 1. Nikšić Fieldbefore construction of reservoirs

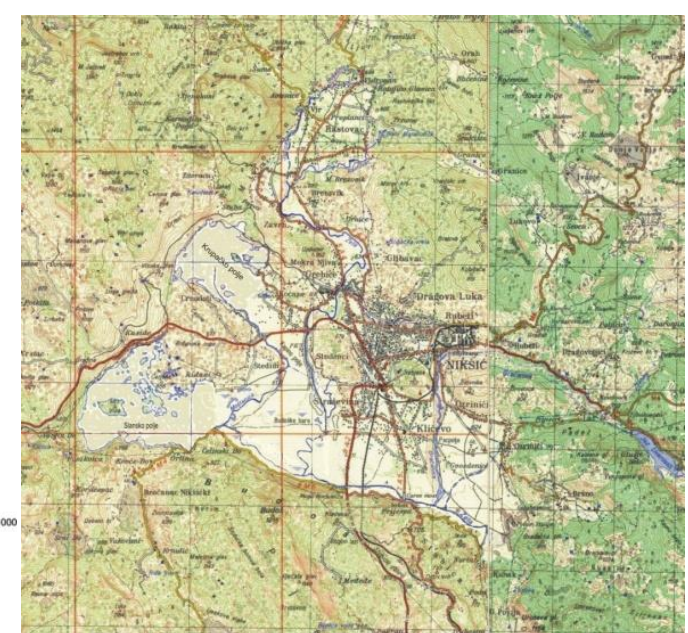

Figure 2: Overview map- model 2. Nikšić

Fieldbefore construction of reservoirs

\section{PRESENT-DAY HYDROLOGICAL CHARACTERISTICS OF THE FIELD}

The construction of the Upper Zeta Hydrological System led to drastic changes in the hydrological conditions in the field itself. The basic and largest change which came about in the field was the formation of the reservoirs of Krupac, Slano and Vrtac. Krupac Reservoir was one of the first artificial reservoirs formed on calciferous terrain in the world. It is formed in Krupac Field which is a morphological unit of Nikšić Field, and (geologically) made up of thick accumulations of clay, with a thickness of around $16 \mathrm{~m}$. The length of Krupac's dam is $1,480 \mathrm{~m}$ and is located at an elevation of $620 \mathrm{~m}$. The reservoir covers a surface area of $5.7 \mathrm{~km}^{2}$ and has a volume of 30 million cubic metresof water. The present-day state of the hydrological features in the area of Krupac is: five springs and four sinkholes, through whichwater is lost, as well as through the injection curtain. Slano Reservoir arose from the redirection of the flow of the River Opačica, which flowed through the south-west part of the field. The dam was made in the profile atOrlina, 1,663 m long with an absolute height of $30 \mathrm{~m}$, and is located at an elevation of $623 \mathrm{~m}$. The bottom of Slano Reservoir is made up of sandy clay, which was formed in four parts, whose thickness is $17 \mathrm{~m}$. Underneath these clay layers lies a calciferous base. The reservoir has a volume of 120 million cubic metres of water, covering an area of 8.89 $\mathrm{km}^{2}$. According to present-day surveys of its hydrographical features there are confirmed to be: 11 springs, seven sinkholes and 12 estavelles (figure 3).Vrtac Reservoir is located east of Slano Reservoir, i.e. is separated from it only by Slano Reservoir's dam. To the south is Mt. Budoš and to the north the Studenac Hills. The length of Vrtac's dam is 2,373 $\mathrm{m}$ and it is located at an elevation of $616.5 \mathrm{~m}$ while the absolute height of the dam is 16 $\mathrm{m}$. This reservoir covers an area of $13.5 \mathrm{~km}^{2}$ and has a volume of 71.8 million cubic metres of water. The injection works which were carried out in the shore part of Lake Vrtac did not produce the desired results, so even today work is being carried out to close up particular sinkholes in order to prevent unplanned loss of water from the lake. Because of the inability to store water for a long time in this reservoir, its contents are used first to supply the needs of PerućicaHydroelectric Plant. The most recent research shows that Vrtac nowadays has four springs, two sinkholes and three estavelles that are activein its accumulation zone. [3] 


\section{SPATIAL MODELLING OF NIKŠIĆ FIELD THROUGH APPLICATION OF THE CARTOGRAPHICAL METHOD}

The basic cognitive meaning of the cartographical method can have its full practical application through the example of its use in the analysis of the spatial relations in Nikšić Field, as well as through the results we obtain via its application. There are three segments which this method enables us to consider and give a realistic picture of the space under analysis.

The first segment, i.e. "The spatial definition of the material subjects and features", can be carried out through both types of consideration.

- The first, spatial localisation, is the localisation of the region which may be used for forming the reservoirs with analysis of the space which they should cover. First of all, it is necessary to define the position of the dams which should partitionoff the parts of the field in which the planned reservoirs will be formed. The next step in the analysis would be modelling of the surface of the lakes at the minimum and maximum water levels in order to determine the surface of the reservoirs, or the confirmed territory that will be flooded at the maximum water level, for the purpose of expropriation of land, relocation of important buildings, (substations, residential buildings, roads, etc.) and planning the time period necessary to complete the project of envisioned works.

- The next step in modelling the spatial elements would be mutual localisation of the shown elements so that the reservoirs formed would make up a single connected unit. Only the linking of the newly-formed reservoirs into one unit provides a true result and justifies the entire work. Linking the reservoirs with a system of channels which will carry away water as needed to a compensation reservoir, which is located in the south-eastern part of the field, from where it leads via a system of pipes to Perućica Hydroelectric Plant.

The second segment, "the temporal correlation of the real-world processes and features and their evolutivity" can also be considered at two different levels.

- The first is the precise definition of the point in time of the display of the features in one model, i.e. of recording the state as it was at the moment before works were started. Producing a model serves several purposes: definition of the surface which will be flooded, planning the time necessary for carrying out the planned activities for constructing new infrastructural objects and decommissioning the old ones, calculation of the costs of expropriating land, calculation of the costs of construction, calculation of the volume of the accumulation and determining its viability, etc.

- As part of this segment of the cartographical method, it is possible to make a second, new model with the assumed appearance of the space which is intended by the construction of new structures, as well as their effect on the space in which it is located and its immediate and wider surroundings. 


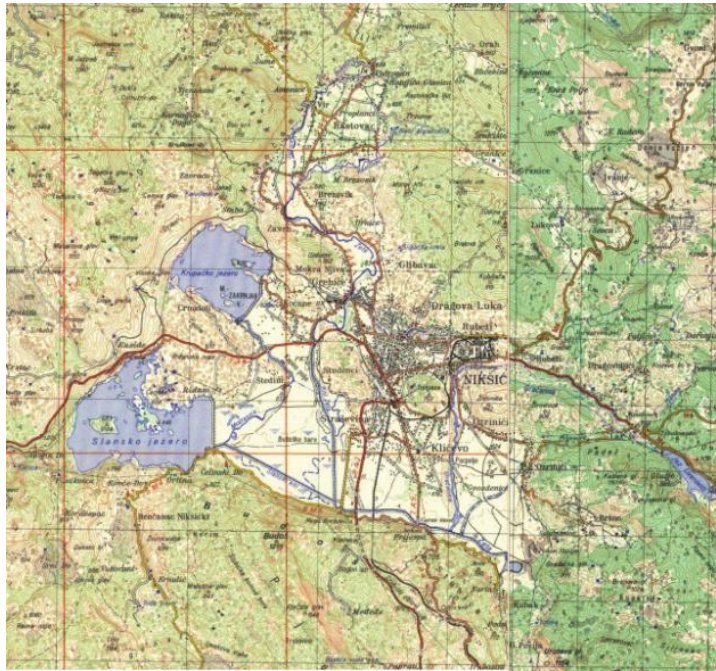

Figure 3: Overview map- model 3. Nikšić Field after construction ofreservoirs

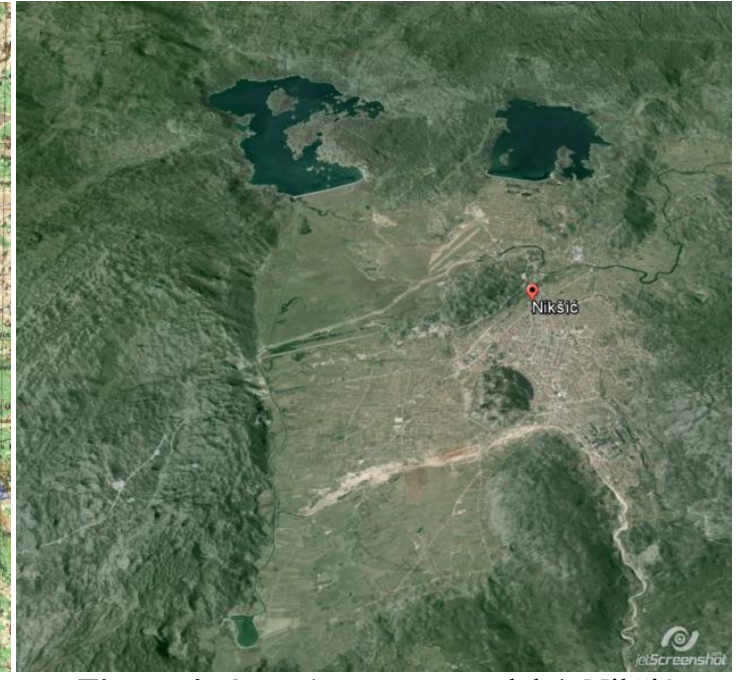

Figure 4: Overview map- model 4. Nikšić Fieldafter construction of reservoirs

The third segment of the cartographical method, "the essential definition of the subject, phenomena and relationships in the real world" is viewed through the possibility of assigning qualitative and quantitative characteristics to the mapped contents. In the given example it is possible to confirm all the important factors that can either positively or negatively affect the entire project and work on removing the obstacles or, rather, improving the general characteristics of the space under question. With appropriate models the following can be shown:

- the area which will be taken up by the newly-formed reservoirs;

- the zones of lesser or greater influence on the surrounding region;

- the possible erosion processes which may appear as consequences of the formation of the reservoir, because of the various effects on the reservoir, should be highlighted;

- the effect of the reservoirs on the existing flora and fauna of the area they take up;

- the effect of the reservoirs on future types of flora and fauna in the area which will be formed and their effect on the environment;

- the directions of necessary activities that should be undertaken to open up new opportunities to use new communities and their protection, should be defined.

The digital model of the analysed space may, as mentionedearlier, be undertaken in various ways (one of those shown on figure 4). Some of the listed models (maps, models in thematic cartography, atlases, 3D and 4D models and virtual reality models) must suit the task that has been set. The great progress made in the development of cartographical representations that can provide users with countless combination and different "views" of the space mapped by the model is obvious. These different "views" are obtained by changing the characteristics or conditions that we can surmise during the research process (example given in figure 5). 


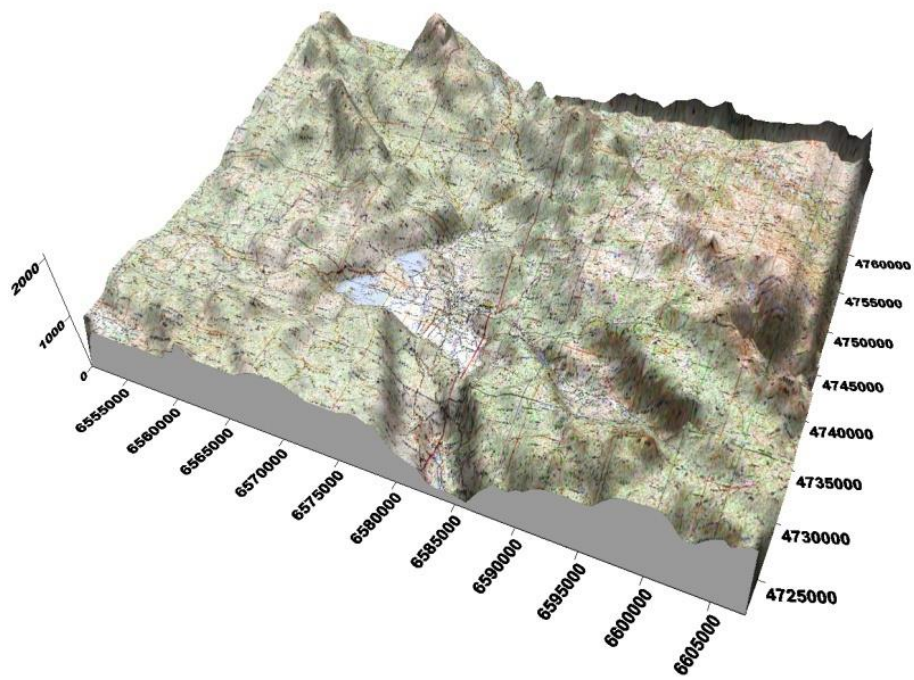

Figure 5: 3D model of Nikšić field

\section{CONCLUSION}

In considering the modern-day types of representation that are used for displaying spatial relations, we see that their evolution has a long history. From ash, tanned hide and papyrus, all the way through printing presses, progress and development has been made in cartography as a science, leading to computer-generated maps at the end of the last century. As with every other scientific discipline, cartography has developed a special and particular scientific method of research. The cartographical method enables the complex and precise representation of a space with a large number of combinations which can be used so that the displayed space can be represented in the best possible way, and afford the user as much information as possible, on the basis of which they can carry out further analysis. Digitisation probably represents the greatest advance in cartographical representation, with the many advantages it has brought to the authors and users of maps. It also is one of the steps in the development of cartography that lie in the next developmental phases of its progress, from which GIS, which represents its future, has arisen.

\section{REFERENCES}

[1]Aalders H. Introduction to Computer-Assisted Cartography, ITC Enschede, 1977.

[2] Barovic G. Kartometrijskaanalizarječnemrežeinjenaprimjena u GIS-u Doktorskadisertacija, PMF, Univerzitet u NovomSadu, Novi Sad, 2010.

[3] Barović G. TransformacijahidrografskihprilikaNikšićkogpolja - kartografskiprikaz, 6 SIMPOZIJUM O ZAŠTITI KARSTA, Belgrade, 2007, pp.11-20.

[4] Frančula M. Digitalnakatografija, Sveučilište u Zagrebu, Geodetskifakultet, 2004.

[5] Ikonović V. Modeli u kartografiji, Zbornik radova LIV, Geografski fakultet Univerzitet u Beogradu, Belgrade, 2006, pp. 229-248.

[6] Lješević M. Kartografski metod u sistemu naučnih metoda i njegovo mjesto $u$ geografiji, Globus, br.13, Belgrade, 1981, pp. 25-60.

[7] Šešić B. Opšta metodologija, Naučna knjiga, 1988. 
International Scientific Conference GEOBALCANICA 2015 